\title{
Susceptibility Analysis of the Mt. Umyeon Landslide Area Using a Physical Slope Model and Probabilistic Method
}

\author{
Sunmin Lee ${ }^{1,2}{ }^{(\mathbb{C}}$ Jungyoon Jang $^{3}$, Yunjee Kim ${ }^{2}$, Namwook Cho $^{2}$ and Moung-Jin Lee ${ }^{4, *(1)}$ \\ 1 Department of Geoinformatics, University of Seoul, 163 Seoulsiripdaero, Dongdaemun-gu, Seoul 02504, \\ Korea; smilee@kei.re.kr \\ 2 Environmental Assessment Group, Korea Environment Institute (KEI), 370 Sicheong-daero, Sejong-si 30147, \\ Korea; yunjeekim@kei.re.kr (Y.K.); nwcho@kei.re.kr (N.C.) \\ 3 Spatial Information Business Office Seoul Regional Headquarters, Korea Land and Geospatial Informatix \\ Corporation, Seoul 06053, Korea; jyjang5904@lx.or.kr \\ 4 Center for Environmental Data Strategy, Korea Environment Institute (KEI), 370 Sicheong-daero, \\ Sejong-si 30147, Korea \\ * Correspondence: leemj@kei.re.kr; Tel.: +82-44-415-7314
}

Received: 7 July 2020; Accepted: 13 August 2020; Published: 18 August 2020

check for updates

\begin{abstract}
Every year, many countries carry out landslide susceptibility analyses to establish and manage countermeasures and reduce the damage caused by landslides. Because increases in the areas of landslides lead to new landslides, there is a growing need for landslide prediction to reduce such damage. Among the various methods for landslide susceptibility analysis, statistical methods require information about the landslide occurrence point. Meanwhile, analysis based on physical slope models can estimate stability by considering the slope characteristics, which can be applied based on information about the locations of landslides. Therefore, in this study, a probabilistic method based on a physical slope model was developed to analyze landslide susceptibility. To this end, an infinite slope model was used as the physical slope model, and Monte Carlo simulation was applied based on landslide inventory including landslide locations, elevation, slope gradient, specific catchment area (SCA), soil thickness, unit weight, cohesion, friction angle, hydraulic conductivity, and rainfall intensity; deterministic analysis was also performed for the comparison. The Mt. Umyeon area, a representative case for urban landslides in South Korea where large scale human damage occurred in 2011, was selected for a case study. The landslide prediction rate and receiver operating characteristic (ROC) curve were used to estimate the prediction accuracy so that we could compare our approach to the deterministic analysis. The landslide prediction rate of the deterministic analysis was $81.55 \%$; in the case of the Monte Carlo simulation, when the failure probabilities were set to $1 \%, 5 \%$, and $10 \%$, the landslide prediction rates were $95.15 \%, 91.26 \%$, and $90.29 \%$, respectively, which were higher than the rate of the deterministic analysis. Finally, according to the area under the curve of the ROC curve, the prediction accuracy of the probabilistic model was $73.32 \%$, likely due to the variability and uncertainty in the input variables.
\end{abstract}

Keywords: probabilistic method; Monte Carlo simulation; physical slope model; Mt. Umyeon landslides

\section{Introduction}

Landslides cause substantial economic and social losses, especially in urban areas where many people live. Landslides are destructive and represent the most frequent risk factors in mountainous areas; especially in urban areas where damage to forests and infrastructure, such as buildings and 
roads, can lead to soil erosion and thus land deformation. Therefore, analysis of mitigation risks and countermeasures for mitigation are essential steps in reducing natural disasters.

Geographic information system (GIS)-based landslide susceptibility analysis has been conducted to predict areas with high probabilities of landslides. Based on spatial data constructed from factors that influence landslide occurrence, such as topography, hydrology, forests, and geology, studies have been conducted to estimate landslide susceptibility [1-5]. Many traditional statistical methodologies, such as evident belief function, frequency ratio, analytical hierarchy process, and logistic regression have been applied [5-9]. Recently, machine learning methodologies have been applied to estimate the spatial uncertainty of landslides $[1,4,10,11]$. Typically, decision tree-based models [12], such as random forest and boosted tree models [13,14], have been applied. Support vector machines [15] and artificial neural networks [16,17] are other commonly applied machine learning methods for landslide susceptibility analysis. Various studies analyzed the relationship between landslide location data and the factors that cause landslides and calculate their effects on landslides. There is a disadvantage to this method because it is not possible to conduct landslide susceptibility analysis on target areas before landslides occur when there is no information on the locations of landslides. The landslide damage area in South Korea is expanding every year; thus, in addition to areas where landslides have already occurred, the frequency of new landslides is increasing [18]. Therefore, it is necessary to predict landslide susceptibilities and prepare countermeasures for areas without prior information.

Among the methods for evaluating landslide susceptibilities, physical-model based analysis estimates the stability by treating a slope as a specific physical model and inputting slope information $[19,20]$. This method enables susceptibility analysis regardless of the information about landslide occurrence location information, so it is possible to analyze the susceptibility of an area before landslides occur [21]. Therefore, this analysis method has the advantage of considering the occurrence mechanism and process of landslides and has been reported as one of the most effective techniques of landslide vulnerability and risk analysis [22]. In particular, among the physical slope models, the infinite slope model, which has a similar form of landslide fracture surface and is easier to analyze than other models, is most commonly used $[23,24]$. In addition, probabilistic techniques are used to effectively deal with the spatial variability in the geotechnical properties used as an input into physical slope models and inaccurate results due to complex geological conditions [25-33].

Landslide susceptibility analysis using physical models uses input data related to the topographical and geological characteristics of the slope [34]. In the process of obtaining the geotechnical characteristics, uncertainty occurs due to the spatial variability of the ground and complex geological conditions, which increases the possibility of obtaining incorrect analysis results. Therefore, probabilistic techniques such as Monte Carlo simulation have been used to quantify uncertainty $[26,30,33]$. In addition, studies are being conducted on various hydrogeological models capable of estimating pore water pressure due to rainfall infiltrating underground for the calculation of pore water pressure affecting stability by reducing shear strength of slope materials $[35,36]$

Thus, this study applied a physical model-based method to analyze landslide susceptibility before landslide occurrence. In this study, an infinite slope model was used as the physical slope model, and we used Monte Carlo (MC) simulation for the probabilistic analysis. Information on the actual occurrence of landslides in Mt. Umyeon was used to validate the accuracy of our techniques [37]. Figure 1 shows the detailed workflow used in this study. We used Mt. Umyeon as the study area because an urban landslide occurred here in July 2011. The Mt. Umyeon landslide is a representative example of serious human injury because it was located in the center of the metropolitan area of Seoul. 


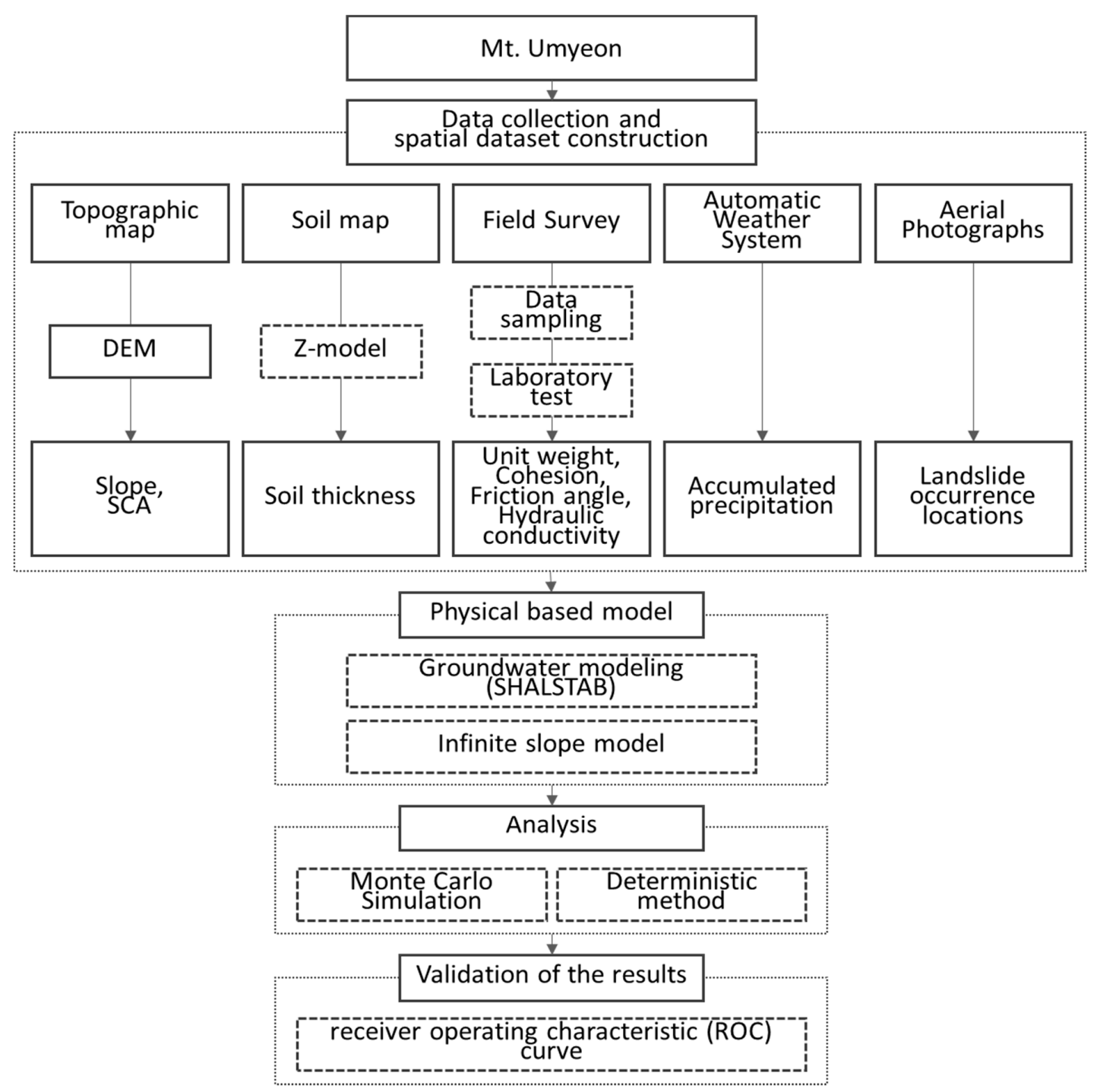

Figure 1. The workflow of this study.

\section{Study Area}

The study area, Mt. Umyeon, is located in Seoul, the capital of the Republic of Korea, within $126^{\circ} 59^{\prime}-127^{\circ} 01^{\prime} \mathrm{E}, 37^{\circ} 27^{\prime}-37^{\circ} 28^{\prime} \mathrm{N}$ (Figure 2). Mt. Umyeon is located at the center of a densely populated area, with highways to the east, rivers and parks to the south, and major cultural facilities around the Mt. Umyeon area. The study area, which was selected based on the type of watershed affected by rainfall, is approximately $22.18 \mathrm{~km}^{2}$ (width: $5.075 \mathrm{~km}$, length: $4.37 \mathrm{~km}$ ). The maximum height of Mt. Umyeon is $293 \mathrm{~m}$; the southern slope has a large slope and a valley, while the northern slope is gentle. Mt. Umyeon is a relatively low mountainous region of gneiss formed by retardation and weathering. The terrain is vulnerable to landslides because the gneiss in the bedrock is distributed with severe weathering and many faults. In addition, the dark veins are partially infiltrated, and overall, weathering is severe and the outcrop is poor [38]. 


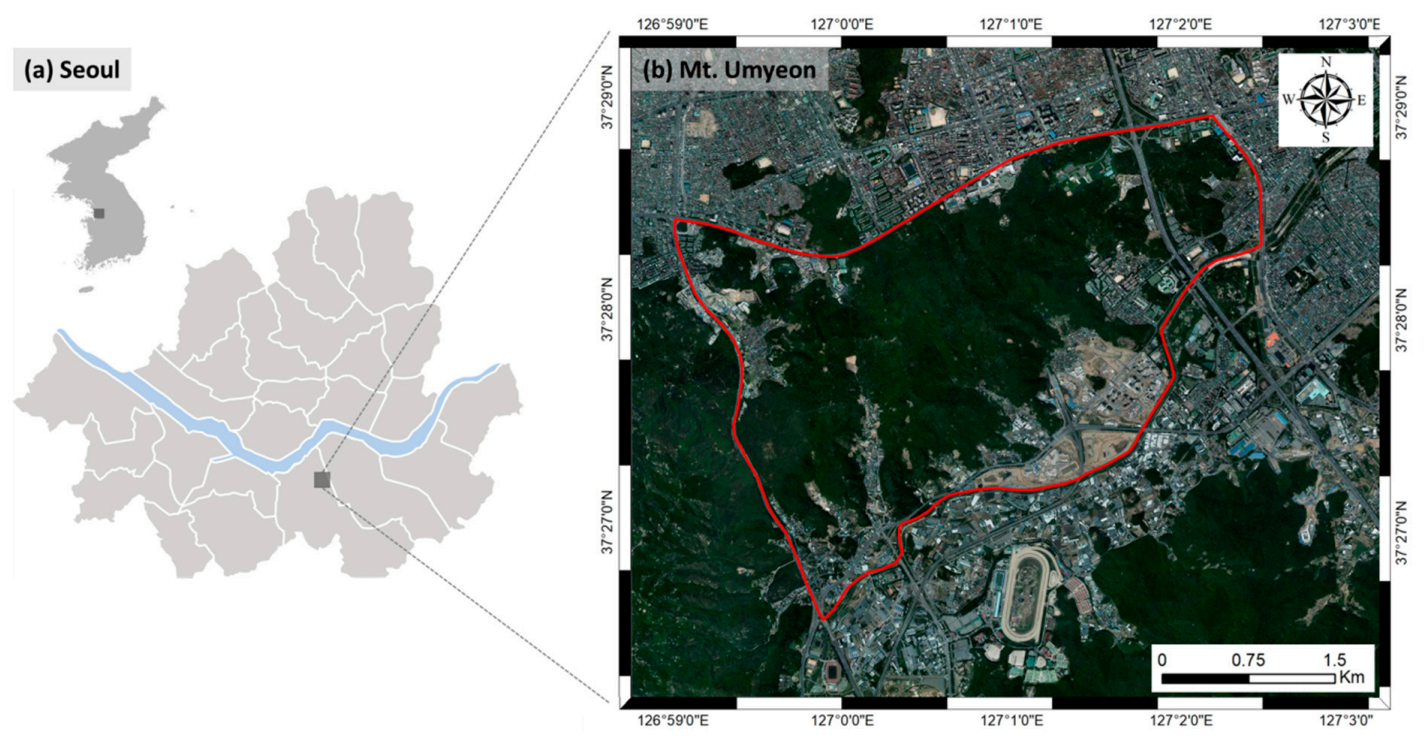

Figure 2. Study area: (a) Seoul; (b) Mt. Umyeon area.

In this region, a number of landslides occurred due to heavy rains, with a cumulative rainfall of $587.5 \mathrm{~mm}$ for 3 days from 26 to 28 July, 2011 [37]. About 150 large and small landslides occurred [38], and the area of debris flow was very wide compared to about 11 square kilometers selected as the radius of the study area (Figure 3). Landslides were presumed to result from heavy rains over a period of about $1 \mathrm{~h}$ following the weakening of ground due to previous heavy rains of 230.0-266.5 mm from about $15 \mathrm{~h}$ before the landslide [38]; the estimated time of the landslide was 09:00 on 27 July, 2011. A number of landslides in the form of debris flow have been reported and landslide occurrence locations were collected based on field investigation and visual analysis of aerial photographs before and after the landslides [38] by points $[3,5,13]$.
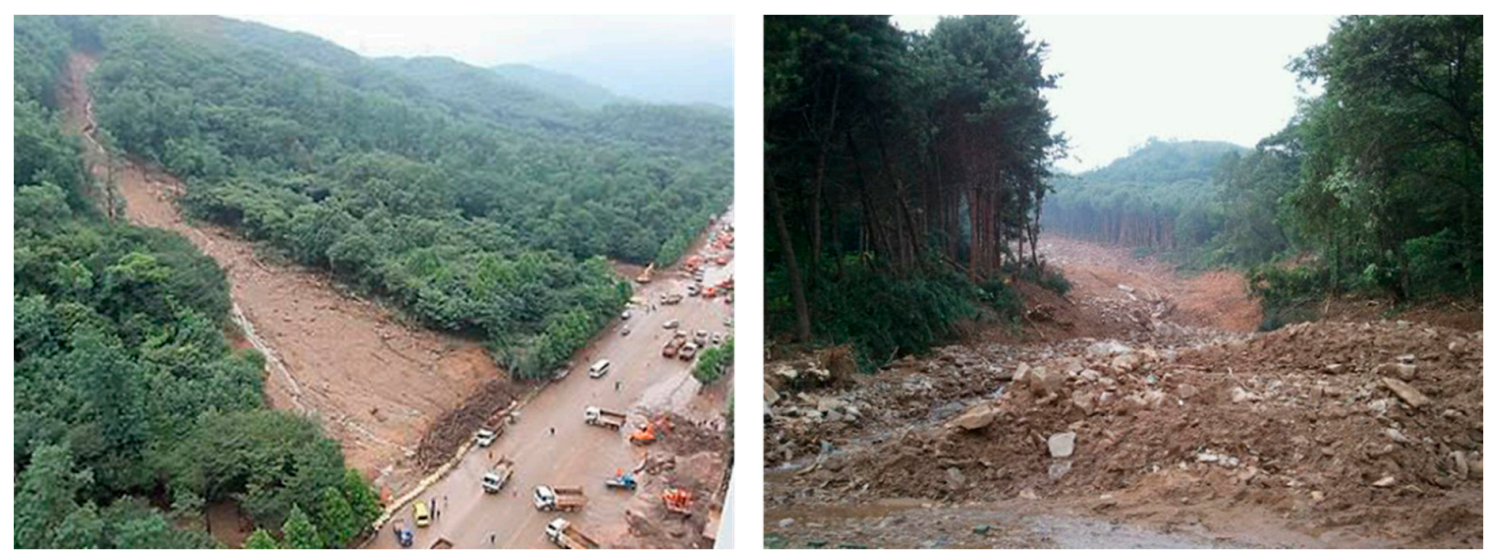

Figure 3. Landslide status on the northern side of Mt. Umyeon in 2011 [39,40].

\section{Spatial Datasets}

Table 1 shows the spatial datasets used in this study. To build the input dataset, all input data were constructed in a raster format with a $5 \times 5 \mathrm{~m}$ grid structure using the ArcGIS 10.3 software. For the analysis of landslide susceptibilities, relevant factors were selected through literature review of previous studies [41-46]. First, a 1: 5000 topographic map was obtained, from which we collated data such as elevation, slope, and specific catchment area. A digital elevation model was constructed by extracting a contour vector layer, including elevation attributes, from a digital topographic map 
(Figure 4a). Finally, the slope and specific catchment area (SCA) were constructed based on the digital elevation model (Figure $4 \mathrm{~b}, \mathrm{c}$ ).

Table 1. Landslide-related factors used to construct spatial database.

\begin{tabular}{|c|c|c|c|}
\hline Data Source & Factors & Data Type & Scale \\
\hline Aerial photograph ${ }^{a}$ & Landslide location & Point & - \\
\hline Topographical map ${ }^{b}$ & $\begin{array}{c}\text { Elevation }[\mathrm{m}] \\
\text { Slope gradient }\left[^{\circ}\right] \\
\text { Specific catchment area (SCA) }\end{array}$ & GRID & $1: 5000$ \\
\hline Soil map ${ }^{c}$ & Soil thickness [m] & Polygon & $1: 25,000$ \\
\hline Field Investigation ${ }^{d}$ & $\begin{array}{c}\text { Unit weight }\left[\mathrm{kN} / \mathrm{m}^{3}\right] \\
\text { Cohesion }[\mathrm{kPa}] \\
\text { Friction angle }[\text { degree] } \\
\text { Hydraulic conductivity }[\mathrm{cm} / \mathrm{s}]\end{array}$ & Point & - \\
\hline Precipitation ${ }^{\mathrm{e}}$ & Rainfall intensity & Point & - \\
\hline \multicolumn{4}{|c|}{$\begin{array}{l}\text { aerial photograph before and after Mt.Umyeon landslides from Kakaomap [47]. }{ }^{\mathrm{b}} \text { Topographical factors were } \\
\text { extracted from digital topographic map by National Geographic Information Institute. }{ }^{\mathrm{c}} \text { The detailed soil map } \\
\text { produced by Rural Development Administration. }{ }^{\mathrm{d}} \text { Field investigation data produced by Korean Geotechnical } \\
\text { Society [38]. }{ }^{\mathrm{e}} \text { The 16-h accumulated precipitation of from seven Automatic Weather System (AWS) observatories by } \\
\text { Korea Meteorological Administration (KMA). }\end{array}$} \\
\hline
\end{tabular}

Second, the z-model was used to build the depth data of the fracture surface. The z-model is a submarine model that reflects the topographic characteristics of the slope by calculating its depth with respect to the elevation [48]. According to the results of ground drilling and seismic surveys by the Korean Society of Civil Engineers [37], the distribution of the soil thickness in the Mt. Umyeon area is $1.18-10.13 \mathrm{~m}$. Therefore, the minimum and maximum depths of the soil in the z-model were set to 1 and $10 \mathrm{~m}$, respectively, and soil thickness was calculated (Figure 4d) [37].

Third, unit weight, cohesion, friction angle, and hydraulic conductivity were obtained through field surveys with indoor experiments. Direct shear tests were conducted on four sampling points (SPs) on the obtained samples of cohesion and friction angle, and borehole shear tests and in-situ permeability tests were conducted at eight drilling points (DPs) in the study area (Figure 5) [38]. Table 2 summarizes the results obtained from this process. In order to interpolate and analyze geological characteristics of the entire study area based on the obtained data [32,41], kriging spatial interpolation analysis from ArcGIS, a spatial processing interpolation technique that reflects the correlation between the distance from the surrounding value and the value located around it, was performed to construct data in raster format (Figure 6).

Table 2. Geotechnical properties of unit weight, cohesion, friction angle, and hydraulic conductivity.

\begin{tabular}{|c|c|c|c|c|}
\hline Name of Sampling Point & $\begin{array}{l}\text { Unit Weight } \\
{\left[\mathrm{kN} / \mathrm{m}^{3}\right]}\end{array}$ & $\begin{array}{c}\text { Cohesion } \\
{[\mathrm{kPa}]}\end{array}$ & $\begin{array}{l}\text { Friction Angle } \\
\text { [degree] }\end{array}$ & $\begin{array}{l}\text { Hydraulic Conductivity } \\
{[\mathrm{cm} / \mathrm{s}]}\end{array}$ \\
\hline SP-1 & 13.770 & - & - & - \\
\hline SP-2 & 13.530 & - & - & - \\
\hline SP-3 & 11.405 & - & - & - \\
\hline SP-4 & 12.405 & - & - & - \\
\hline DP-1 & - & 7.45 & 22.34 & $4.67 \times 10^{-4}$ \\
\hline DP-2 & - & 6.86 & 25.11 & $8.08 \times 10^{-4}$ \\
\hline DP-3 & - & 11.89 & 27.01 & $7.92 \times 10^{-4}$ \\
\hline DP-4 & - & 8.36 & 24.78 & $8.08 \times 10^{-4}$ \\
\hline DP-5 & - & 9.73 & 25.75 & $3.54 \times 10^{-4}$ \\
\hline DP-6 & - & 7.51 & 24.70 & $4.45 \times 10^{-4}$ \\
\hline DP-7 & - & 11.24 & 27.14 & $2.08 \times 10^{-4}$ \\
\hline DP-8 & - & 20.06 & 29.42 & $1.80 \times 10^{-4}$ \\
\hline
\end{tabular}




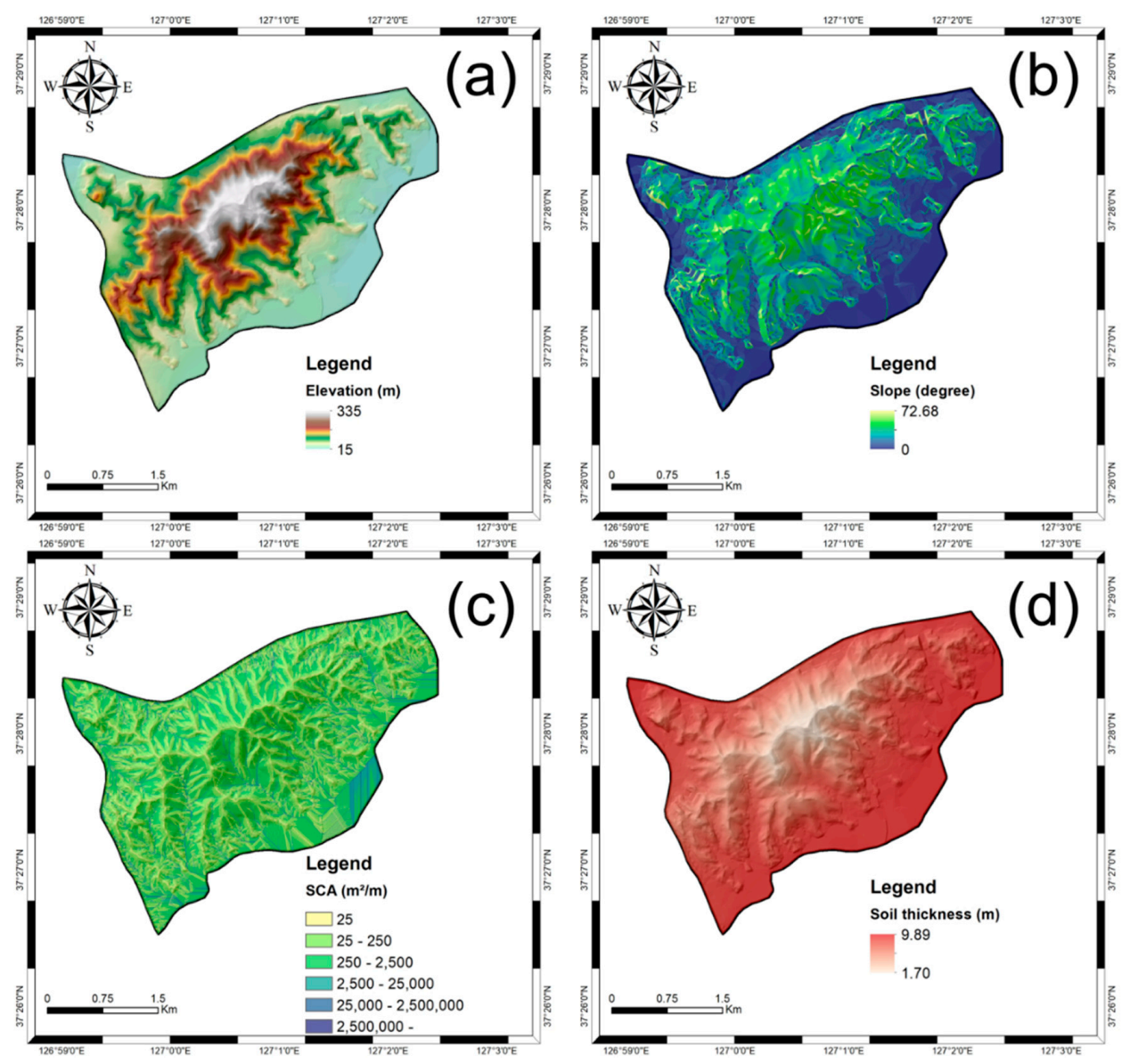

Figure 4. Map showing the input parameters constructed using topographic maps: (a) elevation; (b) slope; (c) specific catchment area (SCA); (d) soil thickness.

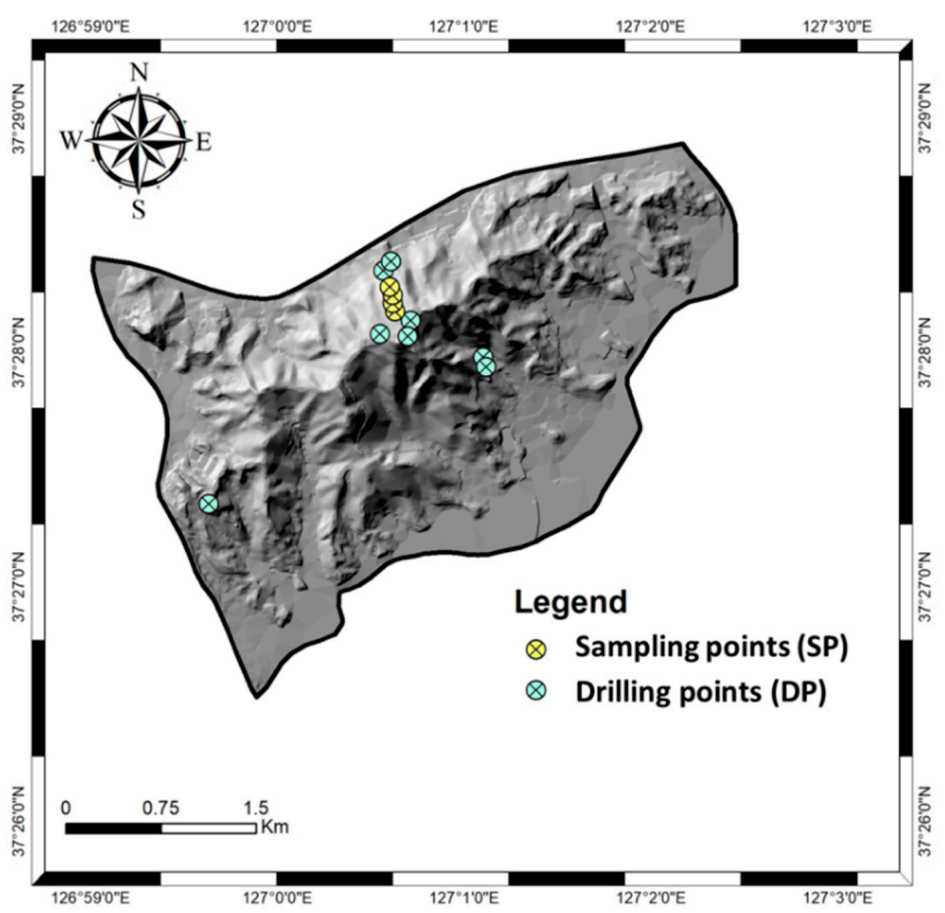

Figure 5. Location map of sampling point for acquisition of geotechnical properties. 


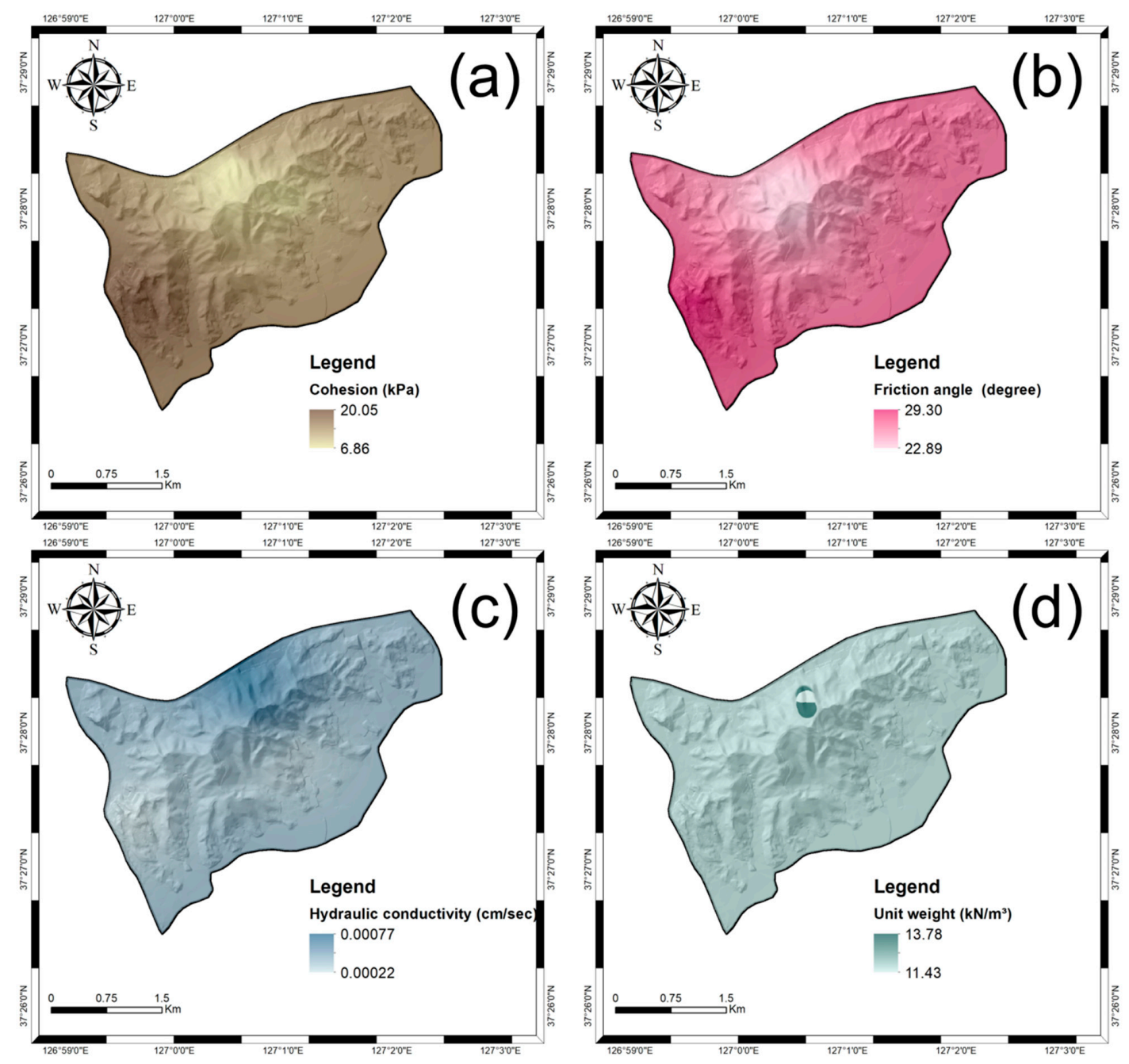

Figure 6. Map showing input parameters constructed using kriging interpolation based on the geotechnical properties of the sampling location (a) cohesion; (b) friction angle; (c) hydraulic conductivity; (d) unit weight.

In sequence, automatic weather system (AWS) data were used to construct rainfall intensity data. The Korea Meteorological Administration (KMA) operates over 510 AWS sites to monitor the atmospheric conditions near the ground in real time. To construct rainfall data in the study area, rainfall data was measured at 1-h intervals at seven AWS stations near Mt. Umyeon (Table 3). The rainfall intensity over the $16 \mathrm{~h}$ from 19:00 26 July to 09:00 27 July, 2011 was obtained to calculate the rainfall intensity at each AWS. Kriging interpolation was also applied to construct rainfall intensity data for the entire study area (Figure 7).

Table 3. Automatic weather system (AWS) observatory information.

\begin{tabular}{|c|c|c|c|c|}
\hline AWS Observatory Name & Number of Stations & Latitude & Longitude & Height above Sea Level (m) \\
\hline Gwanak(ra) & 116 & 37.44526 & 126.96402 & 625 \\
\hline Gangnam & 400 & 37.5134 & 127.04671 & 59 \\
\hline Seocho & 401 & 37.48462 & 127.02601 & 33 \\
\hline Yongsan & 415 & 37.52038 & 126.97611 & 31.73 \\
\hline Namhyeon & 425 & 37.46336 & 126.9855 & 88 \\
\hline Gwanak & 509 & 37.45284 & 126.95015 & 142 \\
\hline Gwacheon & 590 & 37.44028 & 127.00249 & 47 \\
\hline
\end{tabular}




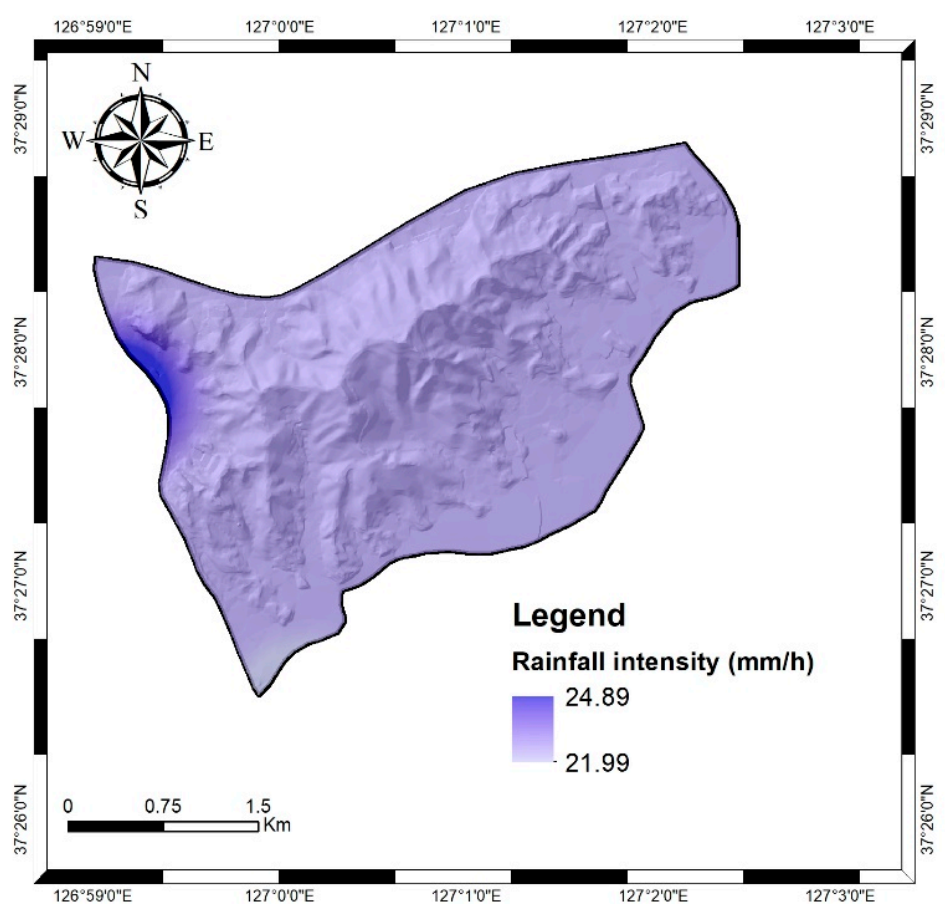

Figure 7. Map showing rainfall intensity using kriging interpolation based on automatic weather system observatory locations.

Finally, a 2011 landslide occurrence map was prepared to validate the analysis. A total of 103 landslide locations were extracted by superimposing a 1: 5000 digital topography onto an aerial photograph with a spatial resolution of $50 \mathrm{~cm}$ before and after the landslide (Figure 8).

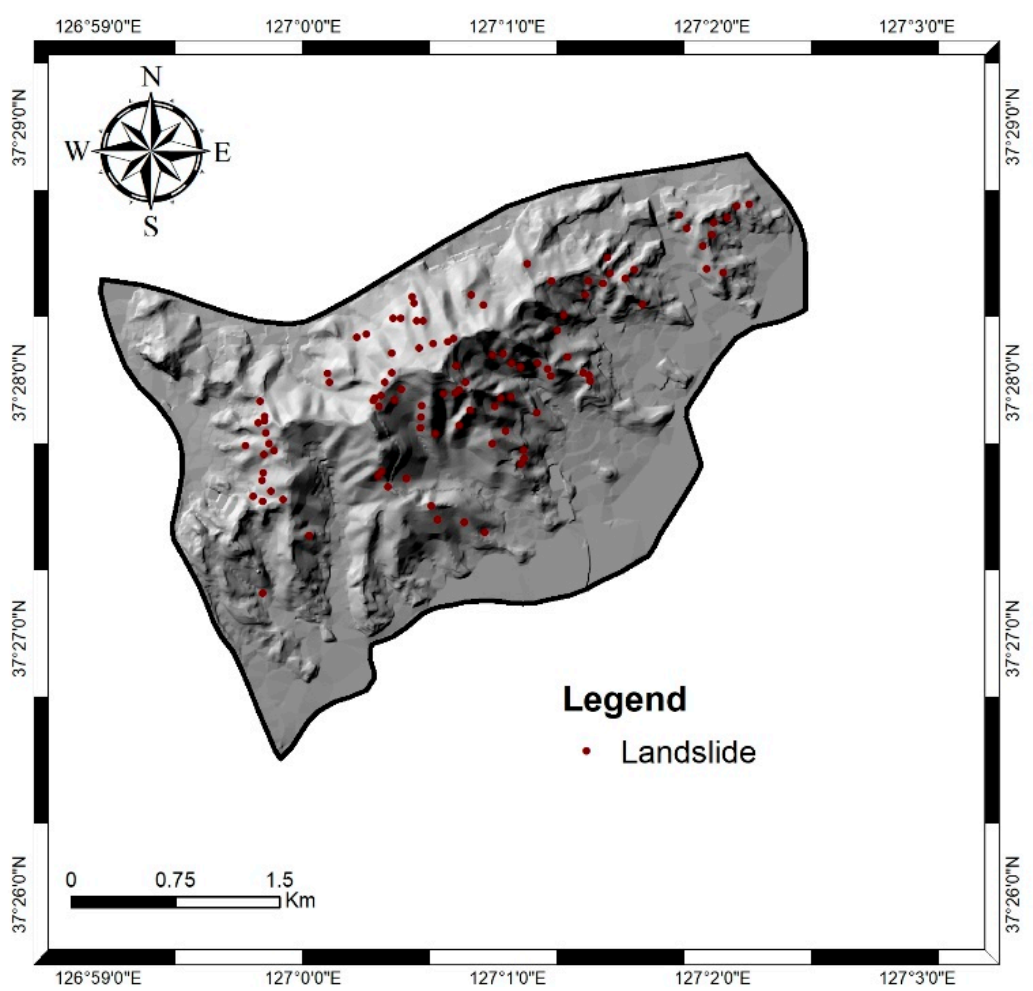

Figure 8. Landslide locations. 


\section{Methodology}

\subsection{Physically Based Model}

We used a physical slope model, an infinite slope, in which the depth of the ground is shorter than the length of the landslide. The infinite slope model is the most suitable model for GIS-based landslide analysis and is widely used to analyze landslides caused by rainfall [49-52]. The stability of the infinite slope model is expressed by the factor of safety (FS), which is the ratio of shear stress to shear strength. The shear stress is the stress that acts on the fracture surface, taking into account the weight and influence of the slope material, whereas the shear strength is based on the action of the pore water pressure on the vertical stress acting perpendicularly to the fracture surface. Therefore, an FS value of less than 1 indicates a destructive state; and is expressed as [53]:

$$
\mathrm{FS}=\frac{c+\left(\gamma D-\gamma_{w} z_{w}\right) \cos ^{2} \alpha \tan \varnothing}{\gamma D \sin \alpha \cos \alpha}
$$

where $c$ is the cohesion $\left[\mathrm{kN} / \mathrm{m}^{3}\right], \gamma$ is the unit weight of the slope material $\left[\mathrm{kN} / \mathrm{m}^{2}\right], D$ is the depth of the slope $[\mathrm{m}], \gamma_{w}$ is the unit weight of water $\left[\mathrm{kN} / \mathrm{m}^{2}\right], z_{w}$ is the groundwater level $[\mathrm{m}], \alpha$ is a gradient of the slope [degree], and $\varphi$ is a frictional angle [degree]. The SHALlow landsliding STABility model (SHALSTAB) was used, which is based on the distributed hydrological model [36] and wet index of the infinite slope stability model, to calculate the groundwater level $\left(z_{w}\right)$. SHALSTAB is a hydraulic model that considers only the ground flow while ignoring the outflow of the surface in the hydraulic model proposed by [54], which considers the flow and surface runoff in shallow ground. It is expressed as follows:

$$
\frac{q \times a}{T \times \sin \alpha \times b}=\frac{z_{w}}{D}=w
$$

where $q$ is rainfall $[\mathrm{m} /$ day $], a$ is the watershed area $\left[\mathrm{m}^{2}\right], b$ is the width of the contour line $[\mathrm{m}]$, and $T$ is transmissivity $\left[\mathrm{m}^{2} /\right.$ day]. Furthermore, $w$ is the wetness index, which is the ratio of the groundwater level to the depth of the slope $\left(z_{w} / D\right)$, the relative depth of the actual groundwater level with respect to the slope. The wetness index $w$ is between 0 and 1; its maximum value is 1 because the groundwater level does not exceed the depth of the slope. The groundwater level is expressed as:

$$
\mathrm{w}=\operatorname{Min}\left(\frac{q \times a}{T \times \sin \alpha \times b}, 1\right)
$$

\subsection{Monte Carlo Simulation}

In order to calculate the safety factor through a mathematical model, input data such as shear strength (cohesion force and friction angle) of the ground or groundwater level are required. However, these data are usually obtained through limited field surveys or indoor experiments, which is absolutely insufficient compared to the size of a wide area. Uncertainty intervenes in these data [55]. In this study, the probabilistic analysis technique was applied to quantitatively consider uncertainty and reflect it in the analysis. Such methods can be used to estimate the probability that the value of a state function satisfies a threshold by assuming that the input variable is randomly selected from a specific distribution. The probabilistic analysis method replaces the safety factor to evaluate the risk of slope using the probability of failure and is evaluated as the most effective method to quantify uncertainty among the various techniques proposed so far.

Probabilistic methods include MC simulation, first-order second moment (FOSM), the point estimate method (PEM), etc. FOSM and PEM are approximate methods, so their accuracy is relatively low compared to MC simulation [31,56]. MC simulation can represent the variability of input variables by randomly generating input variables, and is suitable for analyzing one or more random variables [57]. In this study, analysis was performed using Monte Carlo simulation among the probabilistic analysis techniques. 
The MC simulation method first determines the model of the state function. The state function used in landslide susceptibility analysis depends on FS; and we calculate the probability of failure, which is the probability that FS is less than 1 . Second, the probability distribution of the input variables is calculated. Because information about the probability distribution of input variables is not available, this is considered to be a normal distribution with an appropriate average and standard deviation $[28,32,33,58]$. Third, $\mathrm{N}$ random values were extracted from the distribution of input variables, and $\mathrm{N}$ values of FS were calculated by substituting the values of the randomly generated input variables. Finally, the probability of failure, i.e., the proportion of the N FS values that are less than 1, was calculated as follows:

$$
P_{f}=p(F S<1)
$$

\subsection{Applications and Validation}

In our MC simulation, the cohesion and frictional angle were considered as random variables. According to previous studies, the probability distributions of geotechnical characteristics follow a normal or lognormal distribution, so the probability distribution of the input variables was assumed to be normal in this study [59-61]. Since the mean and standard deviation are required to define the distribution of input variables, the average was calculated based on the constructed data, and the standard deviation was calculated from the coefficient of variation. In previous studies, the ranges of the coefficient of variation of the internal friction angle and cohesion were $10-20 \%$ and $25-30 \%$, respectively $[56,62,63]$. Because the entire study area was composed of gneiss and thus the geological characteristics were relatively similar, the minimum value of each coefficient of variation was assumed to be $10 \%$ for the internal friction angle and $25 \%$ for the cohesive coefficient, and the number of repetitions was set to 100,000 .

The probability of failure is established by probabilistic methods, in contrast to the deterministic analysis in which we interpret an area to be unstable when FS is less than 1 [64]. Therefore, based on the results of previous studies, landslide-susceptible areas were classified based on failure probabilities of $1 \%, 5 \%$, and $10 \%$ [64]. We then calculated the landslide prediction rate, which is the ratio of the number of landslides in a landslide-susceptible area. Furthermore, we carried out a deterministic analysis of the same dataset and calculated the FS by taking a simple average of the data. Finally, we compared the results from the MC simulation to those obtained using deterministic techniques.

Finally, the area under the curve (AUC) of the receiver operating characteristic (ROC) was calculated for validation purposes. The $x$-axis of the ROC graph is the ratio of the expected landslide area where it shows high susceptibility of landslides, and the $y$-axis is the probability of landslides. The AUC is calculated from the area under the ROC graph and has values between 0 and 1 . The closer it is to $1(100 \%)$, the higher the accuracy [45].

\section{Result}

The results of the MC simulation are summarized in Table 4 and shown in Figure 9. When a $1 \%$ probability of failure was considered to indicate a susceptible area, $57.75 \%$ and $42.25 \%$ of the study area was found to be unstable and stable, respectively, and the landslide prediction rate was $95.15 \%$. When the susceptible area was set based on a probability of failure of $5 \%$, the unstable area was $54.23 \%$, the stable area was $45.77 \%$, and the landslide prediction rate was $91.26 \%$. When we defined the susceptible areas based on a probability of failure of $10 \%$, the unstable area was $52.02 \%$, the stable area was $47.98 \%$, and the landslide prediction rate was $90.29 \%$. By contrast, according to the deterministic analysis method, the unstable area was $42.72 \%$, the stable area was $57.28 \%$, and the prediction rate, which in this case indicated the proportion of the predicted landslides that occurred, was $81.55 \%$. Additionally, the AUC calculation of the ROC graph of the MC simulation was 0.7332 (73.32\%) (Figure 10). 


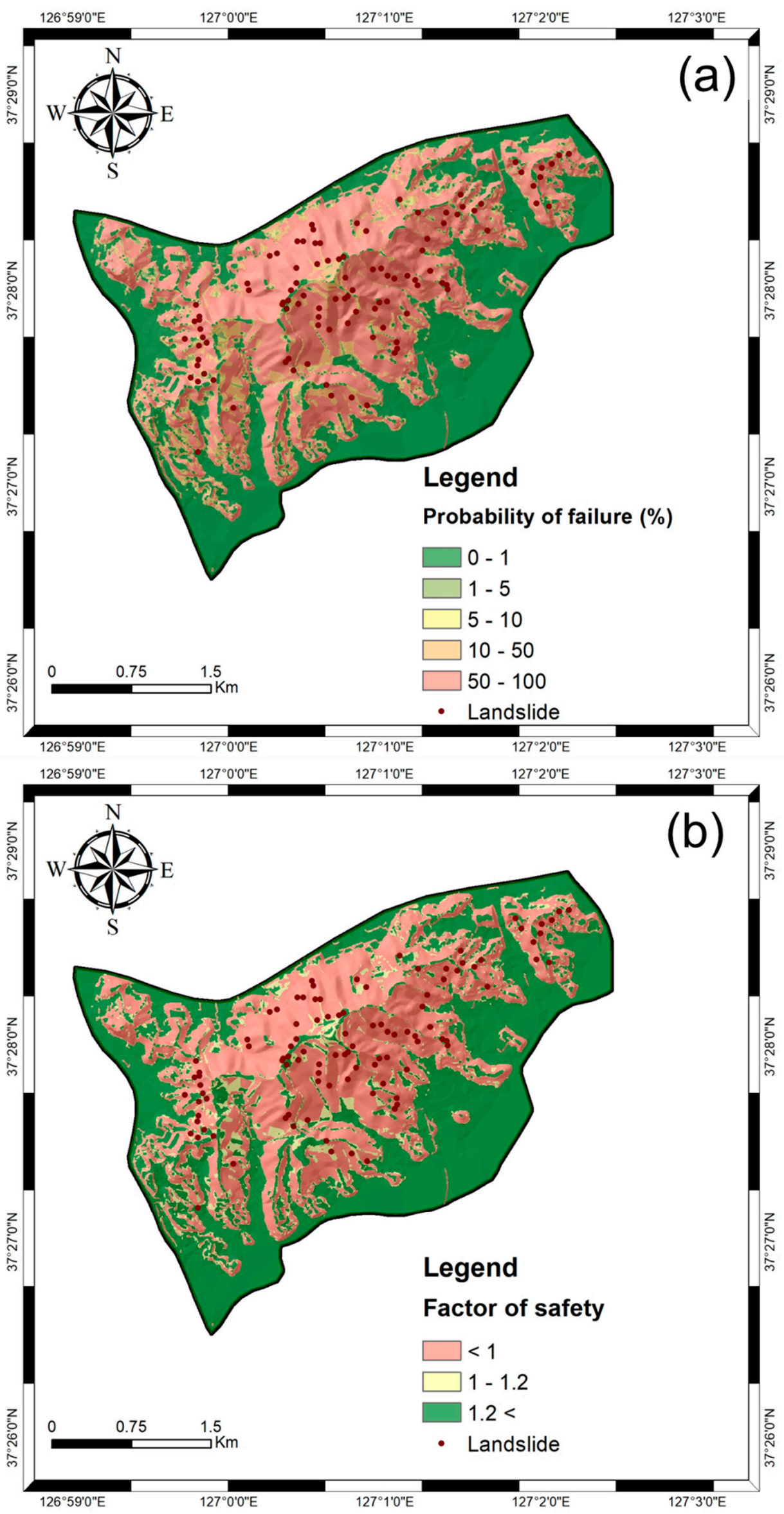

Figure 9. Map showing (a) the probability of failure evaluated using Monte Carlo simulation and (b) the factor of safety evaluated using the deterministic analysis. 


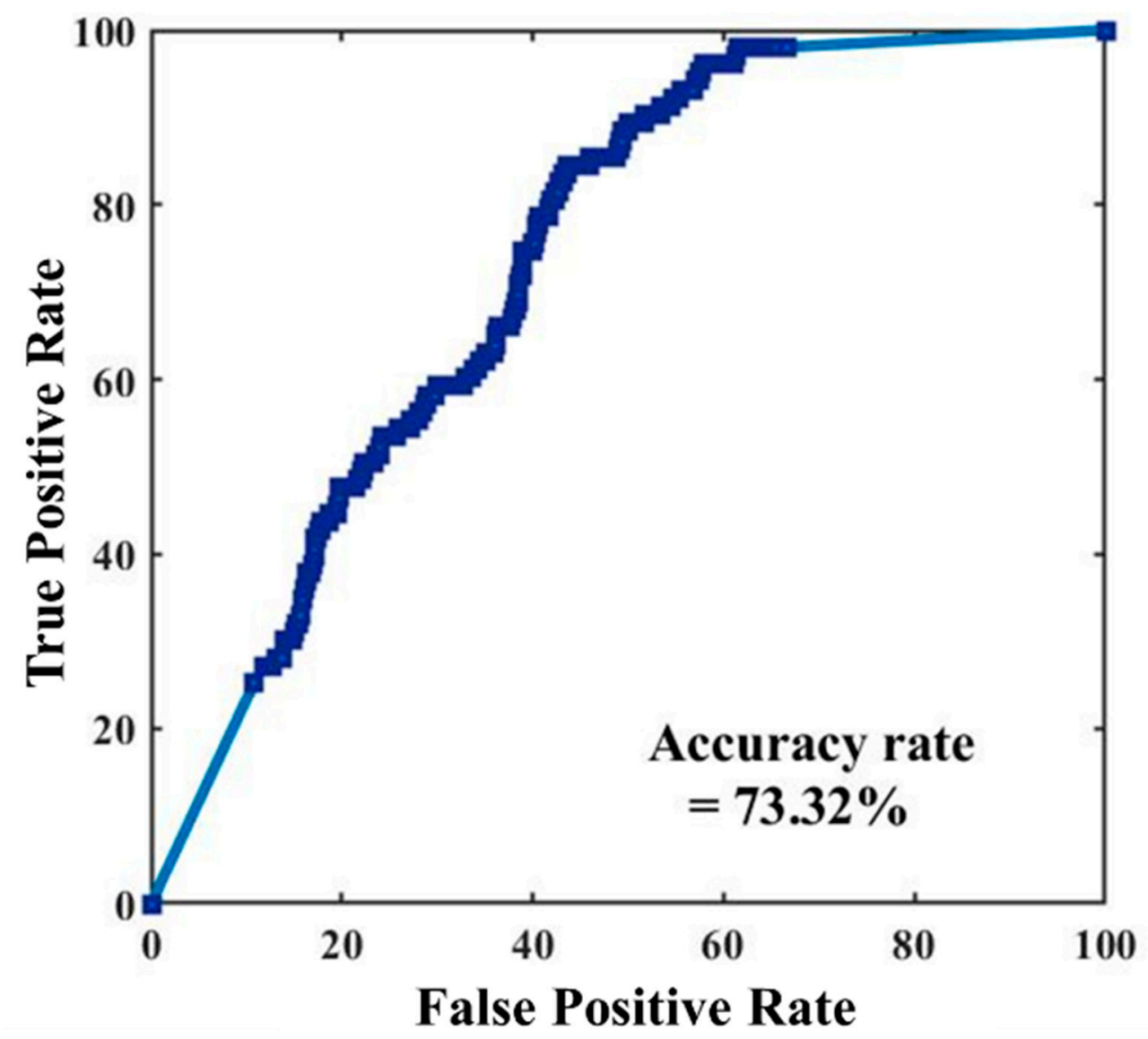

Figure 10. Receiver operating curve of the results from the Monte Carlo simulation.

Table 4. Monte Carlo simulation results.

\begin{tabular}{ccccc}
\hline Method & $\begin{array}{c}\text { Criteria for Establishing } \\
\text { Unstable Area }\end{array}$ & $\begin{array}{c}\text { Stable Area } \\
\text { (\%) }\end{array}$ & Unstable Area (\%) & $\begin{array}{c}\text { Landslide Prediction Rate } \\
\text { (\%) }\end{array}$ \\
\hline Monte Carlo simulation & more than 1\% & 42.25 & 57.75 & 95.15 \\
\hline Monte Carlo simulation & more than $5 \%$ & 45.77 & 54.23 & 91.26 \\
\hline Monte Carlo simulation & more than 10\% & 47.98 & 52.02 & 90.29 \\
\hline Deterministic analysis & less than 1 & 57.28 & 42.72 & 81.55 \\
\hline
\end{tabular}

Based on the results of both analytical methods, we conclude that the stable area occupies more than $40 \%$ of the study area. According to the results of the MC simulation, as the reference probability of failure decreases, the proportion of unstable regions increases with increasing landslide prediction rate. Our MC simulation predicted relatively high proportions of unstable areas and landslide prediction rates compared to the deterministic analysis. An AUC value of 0.7 or more can be interpreted as indicating good predictive performance $[65,66]$. The AUC obtained from the MC simulation $(0.7332)$ was greater than 0.7 , which could explain the high landslide prediction rate. The good predictive performance of the MC simulation is attributed to the variability of the input variables.

\section{Discussion}

In this study, we conducted a landslide susceptibility analysis of the Mt. Umyeon area, a representative example of urban landslide damage. An interpolation method was used to construct data for the entire study area because we could only obtain subsurface data and geotechnical characteristics for a few points. In addition, it was infeasible to obtain sufficient data to infer the probability distribution due to the cost and constraints of acquiring the actual property values, so we 
assumed the probability distribution to be normal. Since it was difficult to obtain a sufficient amount of field survey data compared to the scope of the study area, but it was difficult to apply the unsaturated soil theory, which requires many experimental values and well reflects the behavior of the groundwater level of the actual ground; saturated soil theory with relatively simple interpretation was applied in this study. In addition, several hydraulic parameters were assumed based on existing studies. Therefore, a more accurate groundwater model can be constructed with sufficient data on hydraulic parameters obtained through experiments. Future studies should increase the number of data acquisition points and experiments at each point to compensate for these limitations.

The results of the landslide susceptibility analysis of the Mt. Umyeon area can be summarized as follows. The MC simulation results showed that the landslide prediction rate $(90.25,91.26$, and 95.15\%) was significantly higher than the landslide prediction rate $(81.55 \%)$ of the deterministic method. Comparing the results of the deterministic analysis method and the MC simulation, which is a probabilistic analysis method, by using the coincidence ratio with the location coordinate of the landslide, the landslide prediction rate of $8.7 \%$ to $13.6 \%$ is higher than the deterministic analysis method. Through these results, the probability analysis method can be applied considering the variability of the rainfall intensity, so accuracy can be improved by considering the uncertainty inherent in the rainfall intensity. MC simulation result also yielded a high AUC value (0.7332). We attributed this improvement in results to the fact that $\mathrm{MC}$ simulation can include the variability and uncertainty of the input variables. Moreover, the proportion of unstable areas around Mt. Umyeon exceeded $40 \%$. This is thought to be due to the weathered gneiss distributed throughout the area and the high rainfall intensity.

\section{Conclusions}

Following the Mt. Umyeon landslide, a representative landslide case in the Seoul metropolitan city, South Korea, it has become necessary to analyze landslide susceptibility. The purpose of this study is to analyze the susceptibility of landslide disasters considering uncertainty before the occurrence of widespread landslides. Analysis based on physical slope models can be used to evaluate landslide susceptibility in areas without prior landslide occurrence. A spatial database of Mt. Umyeon, the study area, was constructed and analyzed by applying it to the infinite slope model that is similar to the characteristics of landslide occurrence in the study area. In addition, landslide susceptibility was applied and analyzed based on a physically based model and MC simulation, a probabilistic analysis technique considering uncertainty. An infinite slope model was used as the physically based model. In the GIS environment, it was possible to analyze landslide susceptibility in the study area, and by using an infinite slope model and using probabilistic techniques, it was possible to evaluate the landslide susceptibility as a quantitative indicator of probability of failure. Furthermore, to evaluate the accuracy of our landslide predictions, we applied a deterministic method and compared the results. Finally, the accuracy of the landslide prediction was calculated based on the AUC.

This study confirms that it is possible to evaluate high-accuracy landslide susceptibility without prior information of landslide occurrences by combining a physical slope model with probabilistic method. By varying the reference probability of failure from $1 \%$ to $10 \%$ in the MC simulation, it was possible to adjust the safety level as needed. This means that the reference failure probability can be varied according to the purpose of analysis. For example, a susceptibility map with a high standard probability of failure should be used to determine the locations of disaster prevention structures to minimize costs. Conversely, if the danger zone is temporarily set to minimize human damage, the susceptibility map should be based on the minimum probability of failure. In this way, the same dataset and probabilistic technique can be used for different purposes.

To prevent a repeat of the damage incurred by the Mt. Umyeon landslide, it is necessary to carry out landslide susceptibility studies of areas where landslides have not occurred. In particular, prior landslide susceptibility analysis should be carried out in areas with high population densities to minimize large-scale damage. The methodology presented herein can be used to prepare measures to reduce 
the damage caused by landslides by analyzing landslide susceptibilities in areas without landslide occurrence data, where landslides have not occurred previously. Furthermore, this methodology can be applied to various regions by extracting input factors by setting an infinite slope model that reflects regional characteristics in consideration of landslide characteristics.

Author Contributions: Conceptualization, S.L. and M.-J.L.; data curation, S.L. and J.J.; formal analysis, Y.K. and N.C.; funding acquisition, M.-J.L.; investigation, J.J. and S.L.; methodology, J.J., Y.K. and N.C.; resources, S.L. and M.-J.L.; software, J.J.; validation, J.J., Y.K. and N.C.; supervision, M.-J.L.; visualization, S.L. and J.J.; writing—original draft, J.J.; writing—review and editing, S.L. and M.-J.L. All authors have read and agreed to the published version of the manuscript.

Funding: This research was conducted at Korea Environment Institute (KEI) with support from Basic Science Research Program through the National Research Foundation of Korea (NRF) funded by the Ministry of Education (NRF-2018R1D1A1B07041203). This research was also supported by a grant (20010017) of R\&D Program of Responding Technology to Climate Disaster such as Heat wave, funded by Ministry of Interior and Safety (MOIS, Korea).

Conflicts of Interest: The authors declare no conflict of interest.

\section{References}

1. Hong, H.; Shahabi, H.; Shirzadi, A.; Chen, W.; Chapi, K.; Ahmad, B.B.; Roodposhti, M.S.; Hesar, A.Y.; Tian, Y.; Bui, D.T. Landslide susceptibility assessment at the Wuning area, China: A comparison between multi-criteria decision making, bivariate statistical and machine learning methods. Nat. Hazards 2019, 96, 173-212. [CrossRef]

2. Zhao, X.; Chen, W. Optimization of Computational Intelligence Models for Landslide Susceptibility Evaluation. Remote Sens. 2020, 12, 2180. [CrossRef]

3. Lee, S.; Lee, M.-J.; Jung, H.-S.; Lee, S. Landslide susceptibility mapping using naïve bayes and bayesian network models in Umyeonsan, Korea. Geocarto Int. 2019, 1-15. [CrossRef]

4. Pham, B.T.; Prakash, I.; Singh, S.K.; Shirzadi, A.; Shahabi, H.; Bui, D.T. Landslide susceptibility modeling using Reduced Error Pruning Trees and different ensemble techniques: Hybrid machine learning approaches. Catena 2019, 175, 203-218. [CrossRef]

5. Son, J.; Suh, J.; Park, H.-D. GIS-based landslide susceptibility assessment in Seoul, South Korea, applying the radius of influence to frequency ratio analysis. Environ. Earth Sci. 2016, 75, 310. [CrossRef]

6. Akgun, A.; Türk, N. Landslide susceptibility mapping for Ayvalik (Western Turkey) and its vicinity by multicriteria decision analysis. Environ. Earth Sci. 2010, 61, 595-611. [CrossRef]

7. Lee, S.; Lee, M.-J.; Jung, H.-S. Data mining approaches for landslide susceptibility mapping in Umyeonsan, Seoul, South Korea. Appl. Sci. 2017, 7, 683. [CrossRef]

8. Park, S.; Choi, C.; Kim, B.; Kim, J. Landslide susceptibility mapping using frequency ratio, analytic hierarchy process, logistic regression, and artificial neural network methods at the Inje area, Korea. Environ. Earth Sci. 2013, 68, 1443-1464. [CrossRef]

9. Pradhan, A.M.S.; Kim, Y.-T. Spatial data analysis and application of evidential belief functions to shallow landslide susceptibility mapping at Mt. Umyeon, Seoul, Korea. Bull. Eng. Geol. Environ. 2017, 76, 1263-1279. [CrossRef]

10. Bui, D.T.; Tsangaratos, P.; Nguyen, V.-T.; Van Liem, N.; Trinh, P.T. Comparing the prediction performance of a Deep Learning Neural Network model with conventional machine learning models in landslide susceptibility assessment. Catena 2020, 188, 104426. [CrossRef]

11. Kavzoglu, T.; Colkesen, I.; Sahin, E.K. Machine Learning Techniques in Landslide Susceptibility Mapping: A Survey and a Case Study. In Landslides: Theory, Practice and Modelling; Springer: Berlin/Heidelberg, Germany, 2019; pp. 283-301.

12. Dou, J.; Yunus, A.P.; Bui, D.T.; Merghadi, A.; Sahana, M.; Zhu, Z.; Chen, C.-W.; Khosravi, K.; Yang, Y.; Pham, B.T. Assessment of advanced random forest and decision tree algorithms for modeling rainfall-induced landslide susceptibility in the Izu-Oshima Volcanic Island, Japan. Sci. Total Environ. 2019, 662, 332-346. [CrossRef]

13. Park, S.; Kim, J. Landslide susceptibility mapping based on random forest and boosted regression tree models, and a comparison of their performance. Appl. Sci. 2019, 9, 942. [CrossRef] 
14. Sevgen, E.; Kocaman, S.; Nefeslioglu, H.A.; Gokceoglu, C. A novel performance assessment approach using photogrammetric techniques for landslide susceptibility mapping with logistic regression, ANN and random forest. Sensors 2019, 19, 3940. [CrossRef]

15. Abedini, M.; Ghasemian, B.; Shirzadi, A.; Bui, D.T. A comparative study of support vector machine and logistic model tree classifiers for shallow landslide susceptibility modeling. Environ. Earth Sci. 2019, 78, 560. [CrossRef]

16. Shahri, A.A.; Spross, J.; Johansson, F.; Larsson, S. Landslide susceptibility hazard map in southwest Sweden using artificial neural network. Catena 2019, 183, 104225. [CrossRef]

17. Tian, Y.; Xu, C.; Hong, H.; Zhou, Q.; Wang, D. Mapping earthquake-triggered landslide susceptibility by use of artificial neural network (ANN) models: An example of the 2013 Minxian (China) Mw 5.9 event. Geomat. Nat. Hazards Risk 2019, 10, 1-25. [CrossRef]

18. Korea Forest Service. Detailed Strategy for Primary Policy; Korea Forest Service: Seoul, Korea, 2013.

19. Burton, A.; Bathurst, J. Physically based modelling of shallow landslide sediment yield at a catchment scale. Environ. Geol. 1998, 35, 89-99. [CrossRef]

20. Goetz, J.N.; Guthrie, R.H.; Brenning, A. Integrating physical and empirical landslide susceptibility models using generalized additive models. Geomorphology 2011, 129, 376-386. [CrossRef]

21. Abbott, M.B.; Bathurst, J.C.; Cunge, J.A.; O'Connell, P.E.; Rasmussen, J. An introduction to the European Hydrological System-Systeme Hydrologique Europeen, "SHE", 1: History and philosophy of a physically-based, distributed modelling system. J. Hydrol. 1986, 87, 45-59. [CrossRef]

22. Flentje, P.N.; Miner, A.; Whitt, G.; Fell, R. Guidelines for landslide susceptibility, hazard and risk zoning for land use planning. Eng. Geol. 2007, 102, 3-4.

23. Ho, J.-Y.; Lee, K.T.; Chang, T.-C.; Wang, Z.-Y.; Liao, Y.-H. Influences of spatial distribution of soil thickness on shallow landslide prediction. Eng. Geol. 2012, 124, 38-46. [CrossRef]

24. Santoso, A.M.; Phoon, K.-K.; Quek, S.-T. Effects of soil spatial variability on rainfall-induced landslides. Comput. Struct. 2011, 89, 893-900. [CrossRef]

25. Einstein, H.; Baecher, G. Probabilistic and Statistical Methods in Engineering Geology I. Problem Statement and Introduction to Solution. In Ingenieurgeologie und Geomechanik als Grundlagen des Felsbaues/Engineering Geology and Geomechanics as Fundamentals of Rock Engineering; Springer: Berlin/Heidelberg, Germany, 1982; pp. 47-61.

26. El-Ramly, H.; Morgenstern, N.; Cruden, D. Probabilistic slope stability analysis for practice. Can. Geotech. J. 2002, 39, 665-683. [CrossRef]

27. Hanss, M.; Turrin, S. A fuzzy-based approach to comprehensive modeling and analysis of systems with epistemic uncertainties. Struct. Saf. 2010, 32, 433-441. [CrossRef]

28. Mostyn, G.; Li, K. Probabilistic Slope Analysis-State-of-Play. In Proceedings of the Conference on Probabilistic Methods in Geotechnical Engineering, Canberra, Australia, 10-12 February 1993; pp. 89-109.

29. Mostyn, G.R.; Small, J. Methods of stability analysis. In Soil Slope Instability and Stabilization, 1st ed.; Walker, B.F., Fell, R., Eds.; Balkema: Rotterdam, The Netherlands, 1987; pp. 71-120.

30. Nilsen, B. New trends in rock slope stability analyses. Bull. Eng. Geol. Environ. 2000, 58, 173-178. [CrossRef]

31. Park, H.; West, T. Development of a probabilistic approach for rock wedge failure. Eng. Geol. 2001, 59, 233-251. [CrossRef]

32. Park, H.-J.; West, T.R.; Woo, I. Probabilistic analysis of rock slope stability and random properties of discontinuity parameters, Interstate Highway 40, Western North Carolina, USA. Eng. Geol. 2005, 79, 230-250. [CrossRef]

33. Pathak, S.; Nilsen, B. Probabilistic rock slope stability analysis for Himalayan conditions. Bull. Eng. Geol. Environ. 2004, 63, 25-32. [CrossRef]

34. Lee, J.H.; Park, H.J. Assessment of landslide susceptibility using a coupled infinite slope model and hydrologic model in Jinbu area, Gangwon-do. Econ. Environ. Geol. 2012, 45, 697-707. [CrossRef]

35. Beven, K.J.; Kirkby, M.J. A physically based, variable contributing area model of basin hydrology/Un modèle à base physique de zone d'appel variable de l'hydrologie du bassin versant. Hydrol. Sci. J. 1979, 24, 43-69. [CrossRef]

36. Montgomery, D.R.; Dietrich, W.E. A physically based model for the topographic control on shallow landsliding. Water Resour. Res. 1994, 30, 1153-1171. [CrossRef] 
37. Korean Society of Civil Engineers. Complementary Studies on the Cause of the Umyeonsan(Mt.); Korean Society of Civil Engineers: Seoul, Korea, 2012.

38. Korean Geotechnical Society. Final Report on the Cause of Landslides in Umyeonsan(Mt.) Area and the Establishment of Restoration Measures; Korean Geotechnical Society: Seoul, Korea, 2012.

39. All in Korea. What Are the Causes of Umyeonsan Landslide? Available online: http://www.allinkorea.net/ 22313 (accessed on 1 August 2020).

40. MBC News. Causes of Umyeonsan Landslide, Other than '120 Years of Heavy Rain'. Availabe online: http://d.kbs.co.kr/news/view.do?ncd=2825925 (accessed on 1 August 2020).

41. Jang, J.Y.; Park, H.J. Physically Based Landslide Susceptibility Analysis Using a Fuzzy Monte Carlo Simulation in Sangju Area, Gyeongsangbuk-Do. Econ. Environ. Geol. 2017, 50, 239-250.

42. Jeong, S.; Kim, Y.; Lee, J.K.; Kim, J. The 27 July 2011 debris flows at Umyeonsan, Seoul, Korea. Landslides 2015, 12, 799-813. [CrossRef]

43. Kim, S.; Paik, J.; Kim, K.S. Run-out modeling of debris flows in Mt. Umyeon using FLO-2D. J. Korean Soc. Civ. Eng. 2013, 33, 965-974. [CrossRef]

44. Lee, G.-H.; Oh, S.-R.; Lee, D.-U.; Jung, K.-S. Analysis on Mt. Umyeon Landslide Using Infinite Slope Stability Model. In Proceedings of the Korea Water Resources Association Conference, Jeongseon, Gangwon, Korea, 17-18 May 2012; pp. 737-741.

45. Lee, S.; Lee, M.-J. Susceptibility mapping of Umyeonsan using logistic regression (LR) model and post-validation through field investigation. Korean J. Remote Sens. 2017, 33, 1047-1060.

46. Pradhan, A.M.S.; Kang, H.-S.; Lee, J.-S.; Kim, Y.-T. An ensemble landslide hazard model incorporating rainfall threshold for Mt. Umyeon, South Korea. Bull. Eng. Geol. Environ. 2019, 78, 131-146. [CrossRef]

47. Kakaomap. Kakaomap. Available online: https://map.kakao.com/ (accessed on 1 July 2020).

48. Saulnier, G.-M.; Beven, K.; Obled, C. Including spatially variable effective soil depths in TOPMODEL. J. Hydrol. 1997, 202, 158-172. [CrossRef]

49. Crosta, G.B.; Frattini, P. Rainfall-induced landslides and debris flows. Hydrol. Process. Int. J. 2008, 22, 473-477. [CrossRef]

50. Murphy, W.; Vita-Finzi, C. Landslides and seismicity-An application of remote sensing. In Proceedings of the Thematic Conference on Geologic Remote Sensing, Denver, CO, USA, 29 April-2 May 1991; pp. 771-784.

51. Ward, T.J.; Li, R.-M.; Simons, D.B. Mapping landslide hazards in forest watersheds. J. Geotech. Geoenviron. Eng. 1982, 108, 319-324.

52. Van Westen, C.; Terlien, M. An approach towards deterministic landslide hazard analysis in GIS. A case study from Manizales (Colombia). Earth Surf. Process. Landf. 1996, 21, 853-868. [CrossRef]

53. Coduto, D.P. Geotechnical Engineering: Principles and Practices; Prentice Hall: Upper Saddle River, NJ, USA, 1999.

54. O'loughlin, E. Prediction of surface saturation zones in natural catchments by topographic analysis. Water Resour. Res. 1986, 22, 794-804. [CrossRef]

55. You, K.; Park, Y.; Lee, J.S.J.T.; Technology, U.S. Risk analysis for determination of a tunnel support pattern. Int. J. Adv. Struct. Eng. 2005, 20, 479-486. [CrossRef]

56. Harr, M.E. Reliability-Based Design in Civil Engineering; Dover Publications: Mineola, NY, USA, 1984.

57. Greco, V.R. Efficient Monte Carlo technique for locating critical slip surface. J. Geotech. Eng. 1996, 122, 517-525. [CrossRef]

58. Park, H.-J. The Evaluation of Failure Probability for Rock Slope Based on Fuzzy Set Theory and Monte Carlo Simulation. J. Korean Geotech. Soc. 2007, 23, 109-117.

59. Liu, C.-N.; Wu, C.-C. Mapping susceptibility of rainfall-triggered shallow landslides using a probabilistic approach. Environ. Geol. 2008, 55, 907-915. [CrossRef]

60. Lumb, P. The variability of natural soils. Can. Geotech. J. 1966, 3, 74-97. [CrossRef]

61. Oka, Y.; Wu, T.H. System reliability of slope stability. J. Geotech. Eng. 1990, 116, 1185-1189. [CrossRef]

62. Luo, Z.; Atamturktur, S.; Juang, C.H.; Huang, H.; Lin, P.-S. Probability of serviceability failure in a braced excavation in a spatially random field: Fuzzy finite element approach. Comput. Geotech. 2011, 38, 1031-1040. [CrossRef]

63. Phoon, K.-K.; Retief, J.V. Reliability of Geotechnical Structures in ISO2394; CRC Press: Boca Raton, FL, USA, 2016.

64. Chowdhury, R.; Flentje, P.; Bhattacharya, G. Geotechnical Slope Analysis; CRC Press: Boca Raton, FL, USA, 2009. 
65. Fawcett, T. An introduction to ROC analysis. Pattern Recognit. Lett. 2006, 27, 861-874. [CrossRef]

66. Lee, S.; Hyun, Y.; Lee, S.; Lee, M.-J. Groundwater Potential Mapping Using Remote Sensing and GIS-Based Machine Learning Techniques. Remote Sens. 2020, 12, 1200. [CrossRef]

(C) 2020 by the authors. Licensee MDPI, Basel, Switzerland. This article is an open access article distributed under the terms and conditions of the Creative Commons Attribution (CC BY) license (http://creativecommons.org/licenses/by/4.0/). 